\title{
Development of a toolbox to dissect host-endosymbiont interactions and protein trafficking in the trypanosomatid Angomonas deanei
}

Jorge Morales ${ }^{1 \dagger}$, Sofia Kokkori ${ }^{1 \dagger}$, Diana Weidauer ${ }^{1}$, Jarrod Chapman², Eugene Goltsman², Daniel Rokhsar², Arthur R. Grossman ${ }^{3}$ and Eva C. M. Nowack ${ }^{*}$

\begin{abstract}
Background: Bacterial endosymbionts are found across the eukaryotic kingdom and profoundly impacted eukaryote evolution. In many endosymbiotic associations with vertically inherited symbionts, highly complementary metabolic functions encoded by host and endosymbiont genomes indicate integration of metabolic processes between the partner organisms. While endosymbionts were initially expected to exchange only metabolites with their hosts, recent evidence has demonstrated that also host-encoded proteins can be targeted to the bacterial symbionts in various endosymbiotic systems. These proteins seem to participate in regulating symbiont growth and physiology. However, mechanisms required for protein targeting and the specific endosymbiont targets of these trafficked proteins are currently unexplored owing to a lack of molecular tools that enable functional studies of endosymbiotic systems.
\end{abstract}

Results: Here we show that the trypanosomatid Angomonas deanei, which harbors a $\beta$-proteobacterial endosymbiont, is readily amenable to genetic manipulation. Its rapid growth, availability of full genome and transcriptome sequences, ease of transfection, and high frequency of homologous recombination have allowed us to stably integrate transgenes into the A. deanei nuclear genome, efficiently generate null mutants, and elucidate protein localization by heterologous expression of a fluorescent protein fused to various putative targeting signals. Combining these novel tools with proteomic analysis was key for demonstrating the routing of a host-encoded protein to the endosymbiont, suggesting the existence of a specific endosymbiont-sorting machinery in A. deanei.

Conclusions: After previous reports from plants, insects, and a cercozoan amoeba we found here that also in A. deanei, i.e. a member of a fourth eukaryotic supergroup, host-encoded proteins can be routed to the bacterial endosymbiont. This finding adds further evidence to our view that the targeting of host proteins is a general strategy of eukaryotes to gain control over and interact with a bacterial endosymbiont. The molecular resources reported here establish $A$. deanei as a time and cost efficient reference system that allows for a rigorous dissection of host-symbiont interactions that have been, and are still being shaped over evolutionary time. We expect this system to greatly enhance our understanding of the biology of endosymbiosis.

Keywords: Endosymbiosis, Bacterial endosymbiont, Protein targeting, Homologous recombination, Protist, Trypanosomatid

\footnotetext{
* Correspondence: e.nowack@uni-duesseldorf.de

${ }^{\dagger}$ Equal contributors

${ }^{1}$ Department of Biology, Heinrich-Heine-Universität Düsseldorf, Universitätsstr.

1, 40225 Düsseldorf, Germany

Full list of author information is available at the end of the article
} 


\section{Background}

The impact of bacterial endosymbionts on eukaryote evolution and the Earth's biogeochemical cycles is highlighted by the ubiquitous occurrence of mitochondria and plastids, organelles that evolved as a consequence of endosymbiosis more than a billion years ago $[1,2]$. In the last two decades it has become apparent that there are more recently established bacterial endosymbionts found across the eukaryotic tree of life [3, 4]. These associations engage a broad range of bacterial phyla, represent various levels of integration, and usually provide the host with new physiological capabilities that allow it to colonize and propagate in ecological niches that would otherwise be inaccessible [5].

Advances in genome sequencing technologies have been exploited to greatly enhance our understanding of the physiological basis of many endosymbiotic interactions. The genomes of bacterial endosymbionts tend to become reduced, sometimes down to organellar genome sizes, while functions that are beneficial for the host are retained [6, 7]. Furthermore, the gene repertoire of the host and endosymbiont can become highly complementary, which indicates integration of metabolic processes between the partner organisms [8-10]. Molecular mechanisms that mediate these interactions, however, are only starting to be unveiled. While endosymbionts where initially expected to exchange only metabolites with their host cells, recent evidence has demonstrated that it is not only metabolites, but also host-encoded proteins that can be targeted from the cytoplasm of the host cell to the bacterial symbiont. In the cercozoan amoeba Paulinella chromatophora $>30$ genes originally derived from its cyanobacterial endosymbiont (now an organelle called a chromatophore) were identified in the host nuclear genome [11]. Transcripts from three of these genes were shown to be translated on cytoplasmic ribosomes and their protein products targeted to the chromatophore where they assembled with the chromatophore-encoded subunits of photosystem I [12]. In certain plants and insects, nuclear-encoded peptides have been shown to be routed into their endosymbionts where they regulate/ modulate endosymbiont growth and division [13-15].

However, understanding the molecular mechanisms that underlie metabolic complementation and coordination, protein targeting and import, signaling between symbiotic partners, and synchronization of host and endosymbiont cell cycles is limited. This limitation reflects the lack of sophisticated molecular/genetic tools that can be used to probe endosymbiotic associations, the intrinsic complexity of the multicellular systems that are being explored (e.g. symbiosis in insects and plants), and the need to invest time and resources for establishing and maintaining genetically-modified organisms $[16,17]$. Therefore, developing a molecular toolbox for querying an endosymbiont-harboring protist that is easily grown and has a short generation time would represent a considerable asset to the field of symbiosis research.

The trypanosomatid Angomonas deanei belongs to the Kinetoplastea, a class that includes clinically and economically important pathogens such as Leishmania spp., Trypanosoma brucei, and Trypanosoma cruzi. Angomonas along with the genera Strigomonas and Kentomonas form a monophyletic clade within the Kinetoplastea, the subfamily Strigomonadinae that is characterized by the presence of a single $\beta$-proteobacterial endosymbiont in their cytoplasm [18]. The endosymbiont is enclosed by two membranes and a reduced peptidoglycan layer [19], divides synchronously with the host cell, and is vertically transmitted to progeny cells [20]. Whereas most trypanosomatids are nutritionally fastidious and have a strict requirement for heme and several amino acids, members of the Strigomonadinae can grow in defined media lacking heme and containing a reduced number of amino acids because many metabolites can be synthesized by the endosymbiont and delivered to the host [21-23]. Besides members of the Strigomonadinae, there is a single trypanosomatid species (Novymonas esmeraldas) that is known to have acquired bacterial endosymbionts independently [24].

The full genome of $A$. deanei and its $\beta$-proteobacterial endosymbiont were recently sequenced $[22,25]$. The $0.8 \mathrm{Mb}$ endosymbiont genome is strongly reduced compared to free-living $\beta$-proteobacteria and the complement of encoded proteins suggests tight metabolic cooperation between the endosymbiont and host cell $[22,25]$. As is typical for trypanosomatids, the nuclear genome of $A$. deanei is characterized by a lack of introns and transcription of long polycistronic mRNAs that mature by cleavage into single open reading frames (ORFs) concomitant with the addition of a splice leader (SL) at their 5 '-end and polyadenylation at their 3'-end. The relatively simple trypanosomatid genome organization, with typically high levels of homologous recombination (HR), has allowed for the development of numerous molecular biological tools to probe trypanosomatid physiology [26-28].

$A$. deanei has a doubling time of $\sim 6 \mathrm{~h}$ in standard nutrient broth (see Methods), making propagation and experimentation both efficient and inexpensive. In addition, the genomic structure and availability of molecular tools for dissecting closely related organisms make $A$. deanei a promising endosymbiotic model for developing a powerful system for in depth exploration of molecular mechanisms that govern host-endosymbiont interactions. Here we describe the stable integration of transgenes into the $A$. deanei genome, high level expression of those genes, and the generation of null mutants. Furthermore, combining proteomic analysis with the 
newly developed molecular capabilities, we demonstrate that the host Endosymbiont-targeted Protein 1 (ETP1) is routed to the endosymbiont suggesting the existence of a sorting machinery in $A$. deanei that delivers proteins to the endosymbiont.

\section{Results}

Genome and transcriptome assemblies set the foundation for developing genetic tools

Since the available draft assembly of the $A$. deanei nuclear genome is still highly fragmented (contig N50 = $2.5 \mathrm{~kb}$; [25]), information important for building molecular tools for this protist, including sequences of long genomic contigs spanning multiple genes and expression levels of specific genes, is missing. Therefore, a new genome assembly was generated for $A$. deanei ATCC PRA265. In total, 408 scaffolds totaling $19.3 \mathrm{Mbp}$ of sequence were assembled. These scaffolds comprised 1,884 contigs of total length $17.6 \mathrm{Mb}$, and $1.7 \mathrm{Mb}$ of intra-scaffold gaps (9.0\% of the assembly). Half of the assembly is in 22 scaffolds longer than $300.8 \mathrm{~kb}$ (the scaffold N50 length) and 177 contigs are longer than $28.8 \mathrm{~kb}$ (the contig N50 length). This assembly provides more than 10-fold improvement in linkage relative to the gene-oriented assembly that was already available. This Whole Genome Shotgun project has been deposited at DDBJ/ENA/GenBank under the accession LXWQ00000000. Expression levels of many nuclear genes were inferred from RNAseq analyses (see Additional file 1: Table S1).

\section{Efficient homologous recombination in $A$. deanei}

We hypothesized that, like for other trypanosomatids, $A$. deanei would be amenable to genetic manipulation using HR and transgene expression would occur by read through without the need for a dedicated promoter [28]. The loci for one gene of each, the $\gamma$ - and $\delta$-subfamily of amastins [transcripts "a66;8439" and "a96;12664", respectively (see Additional file 2: Figure S1a); hereafter referred to as $\gamma$ - and $\delta$-amastin], were selected for the site at which a cassette containing a drug resistance marker gene would be inserted because (i) these two amastin genes are highly expressed (Additional file 1: Table S1), (ii) amastin loci have been previously used to enhance expression of heterologous genes in other trypanosomatids $[29,30]$, and (iii) a knockdown of $\delta$ amastin does not seem to affect proliferation of insect stages in other trypanosomatid species [31]. Amastins are surface glycoproteins of unknown function that can be grouped into four subfamilies (termed $\alpha$ to $\delta$ ) and occur in some trypanosomatids as tandemly arrayed multicopy genes [32]. Several members of each subfamily are encoded on the $A$. deanei genome [25], but sequences of the various members of the $\gamma$ and $\delta$-subfamilies differ at the nucleotide and amino acid levels and their intergenic regions show no homology (Additional file 2: Figure S1b, c).

For establishing suitable drug resistance selection markers, first, we determined that $300 \mu \mathrm{g} / \mathrm{ml}$ of either G-418 or hygromycin were sufficient to kill wild-type cells following exposure for less than $48 \mathrm{~h}$ (Fig. 1). Next, four plasmids were constructed (pAdea $\gamma$-ama/Neo, pAdea $\delta$-ama/Neo, pAdea $\gamma$-ama/Hyg, and pAdea $\delta$-ama/ Hyg) carrying a cassette in which the $\gamma$ - or $\delta$-amastin coding sequences (CDS) were replaced by either the neomycin (neo) or hygromycin (hyg) resistance genes that each included $1 \mathrm{~kb}$ each of 5'- and 3'-flanking regions (FR) from the $\gamma$ - or $\delta$-amastin gene (Additional file 2: Figure S2). After excision of the drug resistance marker gene with the genomic flanking regions (restriction sites as shown in Additional file 2: Figure S2), the excised DNA was used to transfect $A$. deanei by electroporation. Transfectants were selected in $500 \mu \mathrm{g} / \mathrm{ml} \mathrm{G-418}$ or hygromycin for approximately 2 weeks, and clonal cultures were obtained by limiting dilutions (see Methods). Analyses of cells transfected with the pAdea $\gamma$-ama/Hyg cassette revealed that HR occurred at high frequency and specifically at the targeted locus, resulting in $\Delta-\gamma$-ama ${ }^{H y g}$ single knock-out (SKO) cell lines, as indicated by (i) the occurrence of an additional PCR product at $3.6 \mathrm{~kb}$ using genomic DNA (gDNA) from transformants (compared to the wild-type gDNA) as a
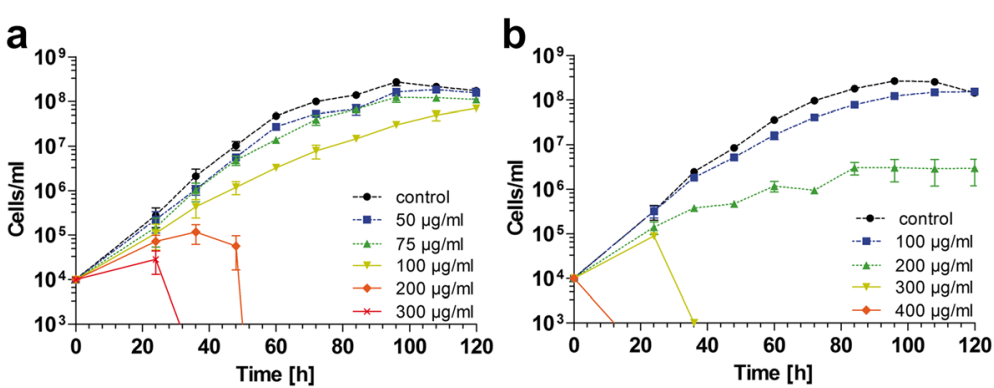

Fig. 1 a G-418 and (b) hygromycin sensitivity of A. deanei. Cultures of wild-type cells grown to mid-log phase were diluted in $10 \mathrm{ml}$ of fresh medium supplemented with the indicated concentration of drug to $1 \times 10^{4} \mathrm{cell} / \mathrm{ml}$ and incubated at $28^{\circ} \mathrm{C}$ without agitation. Cells were counted every $12 \mathrm{~h}$ and the average and standard deviation from three independent cultures were plotted against time 
template and primers that anneal to gDNA just outside of the FR sequences used for targeting the insertion cassette (Additional file 2: Figure S3a); (ii) sequence analysis of PCR products containing the inserted cassette (Fig. 2); (iii) the occurrence of a $4.7 \mathrm{kbp}$ Apa1/SgrA1 gDNA band hybridizing to the hygromycin probe in Southern blot analysis (Fig. 3a); and (iv) reduced hybridization signals of the $\gamma$-amastin probe to Apa1/SgrA1 restricted gDNA of the $\Delta-\gamma$-ama ${ }^{H y g}$ SKO strains relative to wild-type (Fig. 3a, compare WT with lanes 1-3). Also for the remaining 3 plasmids described in Additional file 2: Figure S2, strict HR was observed. Furthermore, integrations of the resistance cassettes were stable for over 2 months even after removing the selection pressure, as demonstrated by the PCR banding patterns of $\Delta-\delta$-ama ${ }^{N e o}$ SKO cell lines (Fig. 4a).

Since trypanosomatids are asexual diploids, the creation of null mutants requires disruption of both alleles of any specific gene. The double knock-out (DKO) $\Delta-\gamma$ ama $^{H y g} / \Delta-\gamma$-ama ${ }^{N e o}$ was readily obtained by transfection of the $\Delta$ - $\gamma$-ama ${ }^{H y g}$ SKO cell line with the Apa1/Sac1 restriction fragment from pAdea $\gamma$-ama/Neo that encodes the neo resistance marker flanked by $\gamma$-amastin FRs (Fig. $3 \mathrm{~b}$ and Additional file 2: Figure S3b). In this case, restricted gDNA from the DKO strains showed no signal when the $\gamma$-amastin gene was used as a hybridization probe (Fig. 3b, panel 3, lanes 1, 2, and 3), but bands of expected sizes were observed when both hyg and neo genes were used as probes (Fig. 3b, panels 4 and 5, lanes 1,2 and 3).

In order to test if both the $\delta$ - and $\gamma$-amastin loci can be highjacked for simultaneous expression of heterologous genes, a $\Delta$ - $\gamma$-ama ${ }^{H y g} / \Delta-\delta$-ama ${ }^{N e o}$ parallel knock-out (PKO) cell line was generated (Fig. $3 \mathrm{c}$ and Additional file 2: Figure S3c). Insertion of the neo marker gene into one allele of the $\delta$-amastin gene is shown in Fig. 3c, panels 6 and 7 , while insertion of the hyg marker gene into one allele of the $\gamma$-amastin locus is shown in Fig. 3c, panels 8 and 9. There were no apparent phenotypical differences (e.g. cell growth) between wild-type and any of the recombinant cell lines generated, suggesting that a SKO or DKO of the $\gamma$-amastin gene, a SKO of $\delta$-amastin, or a PKO of the $\delta$-amastin and $\gamma$-amastin genes are not detrimental to the cells (Fig. 4b), at least under the conditions that we used for growth.

\section{Construction of a vector for heterologous expression of EGFP}

To facilitate protein localization studies in $A$. deanei, we used heterologous expression of the enhanced green fluorescent protein (EGFP). An expression vector (pAEXEGFP) was constructed in which the 5'-FR of the $\delta$ amastin gene was fused to the 5'-end of the neo marker gene followed by the intergenic region between the $A$. deanei glyceraldehyde 3-phosphate dehydrogenase I and II genes (GAPDH IR), a highly conserved trypanosomatid sequence containing all signals necessary for transcript maturation and stability [33, 34], and then EGFP followed by the 3 '-FR of the $\delta$-amastin gene (Fig. $5 \mathrm{a}$, top). A foreign gene (encoding a protein of interest) could be integrated into this vector at the 5' or 3'-end of the EGFP sequence, resulting in expression of an EGFP $\mathrm{N}$ - or C-terminal fusion protein. To achieve targeting of EGFP to various subcellular compartments, the pAEX-EGFP vector was modified by the addition of a peroxisomal targeting signal type 1 (PTS1) to EGFP, (vector pAEX-EGFP-SKL; Fig. 5a, middle), or a mitochondrial targeting peptide (mTP) from the Trypanosoma brucei dihydrolipoyl dehydrogenase (vector pAEX-mito-EGFP; Fig. 5a, bottom) [35]. For transfection, the expression cassettes were excised from the plasmids at the EcoRV restriction sites shown in Fig. 5a.
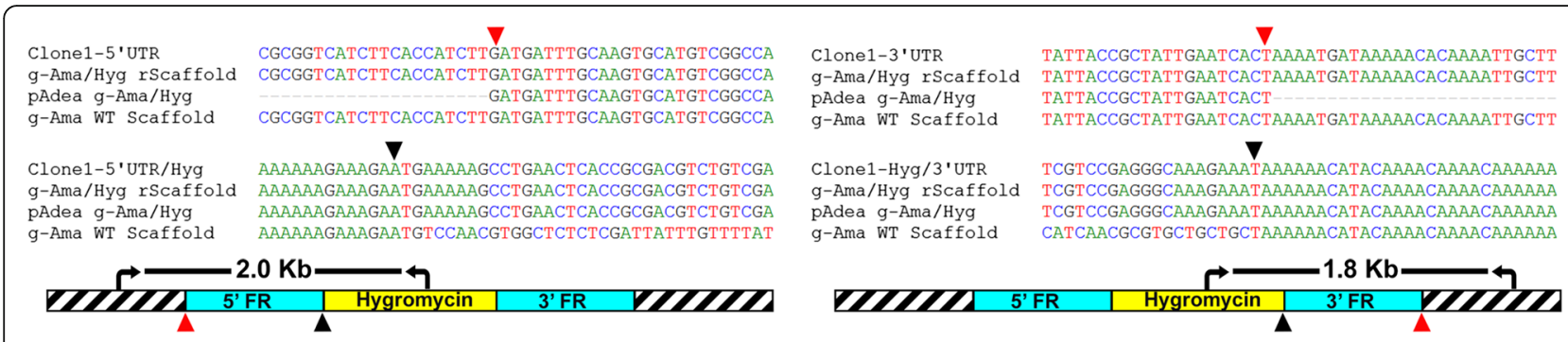

Fig. 2 Sequence analysis confirms insertion of resistance cassette in the $\gamma$-amastin locus. Genomic DNA extracted from $\Delta$ - $\gamma$-ama ${ }^{\text {Hyg }}$ SKO clone 1 (see Additional file 2: Figure S3a) was used as a template for PCR with primers binding to the gDNA outside of the cassette and inside the resistance markers. The PCR products obtained were sequenced. The alignment shows: Clone1-5' or $3^{\prime}$ UTR, sections of the genomic sequence of the transformant resulting from HR between the gDNA and the resistance cassette (pAdea $\mathrm{Y}^{-\mathrm{Ama} a / H y g) ;}$; clone1-5'UTR/Hyg and clone1-Hyg/3'UTR, sections of the genomic sequence of the transformant surrounding the start and stop codon of the hyg gene, respectively; $Y$-Ama/Hyg rScaffold, the expected genomic sequence organization of the recombinant $\Delta-\gamma$-Ama ${ }^{H y g}$ locus; $\gamma$-Ama WT Scaffold, wild-type sequence at the $\gamma$-amastin locus. The map underneath the alignment indicates primer binding sites (arrows) and sizes of resulting PCR products. Red arrowheads indicate the position at which the cassette inserted by HR into the genome and black arrowheads denote the start and stop codon of the hyg and $\gamma$-amastin ORFs. The striped rectangles represent genomic regions upstream and downstream of the insertion sites for the cassettes. Light blue rectangles represent the $5^{\prime}$ - and 3'-flanking regions (FR) of the $\gamma$-amastin gene that are present in the cassette. Yellow rectangles represent hyg 


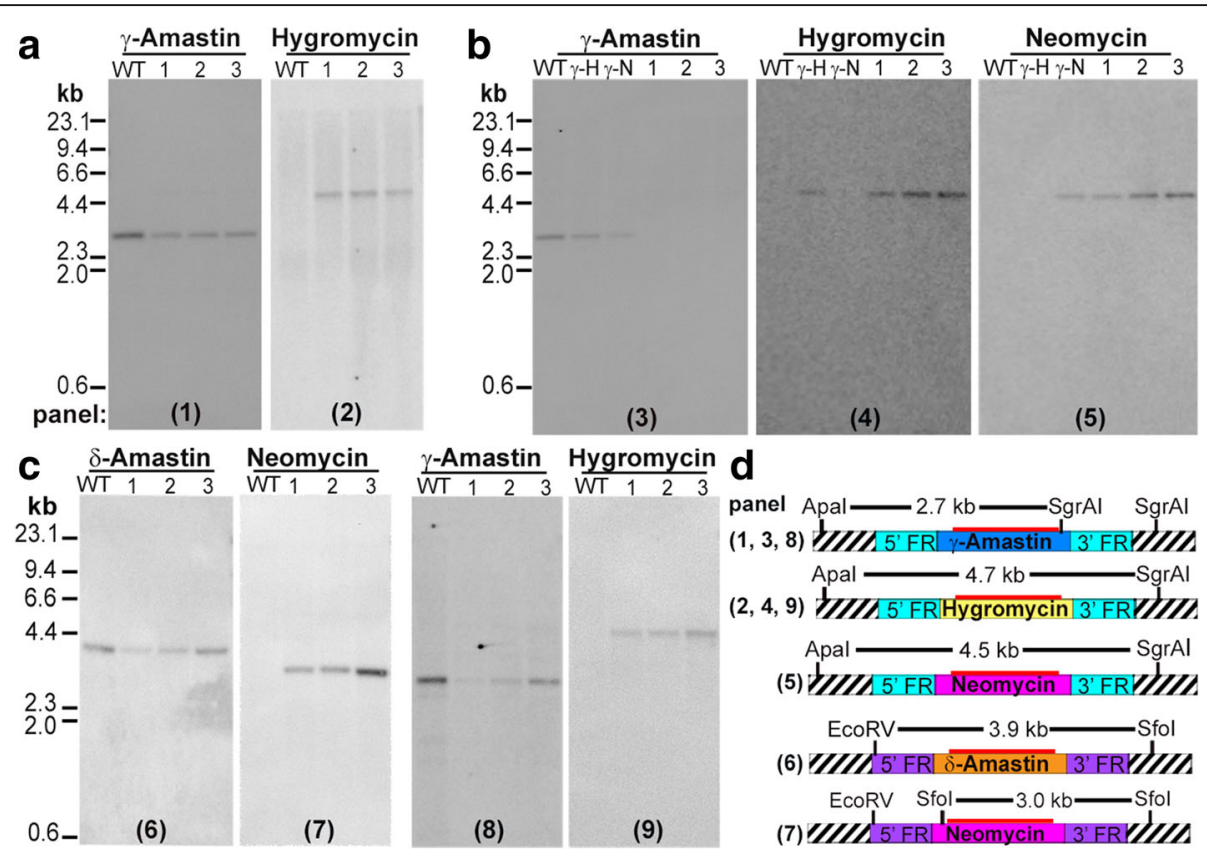

Fig. 3 Homologous recombination in A. deanei. Genomic DNA was restricted with specified enzymes and analyzed by Southern blot hybridizations using probes against $\gamma$-amastin, $\delta$-amastin, hyg, or neo, as indicated above each blot. The wild type (WT) and three clones (1,2, and 3) were analyzed for $\Delta$ - $\gamma$-ama ${ }^{\text {Hyg }}$ SKO (a), $\Delta$ - $\gamma$-ama $a^{H y g} / \Delta$ - $\gamma$-ama ${ }^{N e o}$ DKO (b), and $\Delta$ - $\gamma$-ama $a^{H y g} / \Delta$ - $\delta$-ama $a^{N e o}$ PKO cell lines (c). (a) In the $\Delta$ - $\gamma$-ama ${ }^{H y g}$ SKO cell lines, a band shift of $2 \mathrm{~kb}$ between the $\gamma$-amastin WT locus and the recombinant locus containing hyg could be readily observed in all three clones analyzed, indicating replacement of the first $\gamma$-amastin allele by hyg; (b) a second transfection with a cassette encoding neo targeting the $\gamma$-amastin locus completely abolished the $\gamma$-amastin WT locus in all three $\Delta$ - $\gamma$-ama ${ }^{\text {Hyg }} / \Delta$ - $\gamma$-ama ${ }^{\text {Neo }}$ DKO clones analyzed; as a control, gDNA from the SKO lines $\Delta$ - $\gamma$-ama ${ }^{H y g}(\gamma H)$ and $\Delta$ - $\gamma$-ama ${ }^{\text {Neo }}(\gamma \mathrm{N})$ was tested; (c) transfection of $\Delta$ - $\gamma$-ama ${ }^{\text {Hyg }}$ SKO clone 1 with a cassette encoding neo targeting the $\delta$-amastin locus yielded the $\Delta-\gamma$-ama ${ }^{H y g} / \Delta-\delta$-ama ${ }^{\text {Neo }}$ PKO cell lines. (d) Restriction maps are provided for the various blots. The striped rectangles represent genomic regions up and downstream of the insertion sites for the cassettes, light blue and violet rectangles represent the $5^{\prime}$ - and $3^{\prime}$-flanking regions (FR) of the $\gamma^{-}$and $\delta$-amastin genes, respectively, that are present in the cassettes; blue and orange rectangles represent the $\gamma$ - and $\delta$-amastin ORFs, respectively; and hyg and neo are represented by yellow and pink rectangles, respectively. The red bar above the inserted marker gene highlights the binding region for the DNA probe used for hybridization
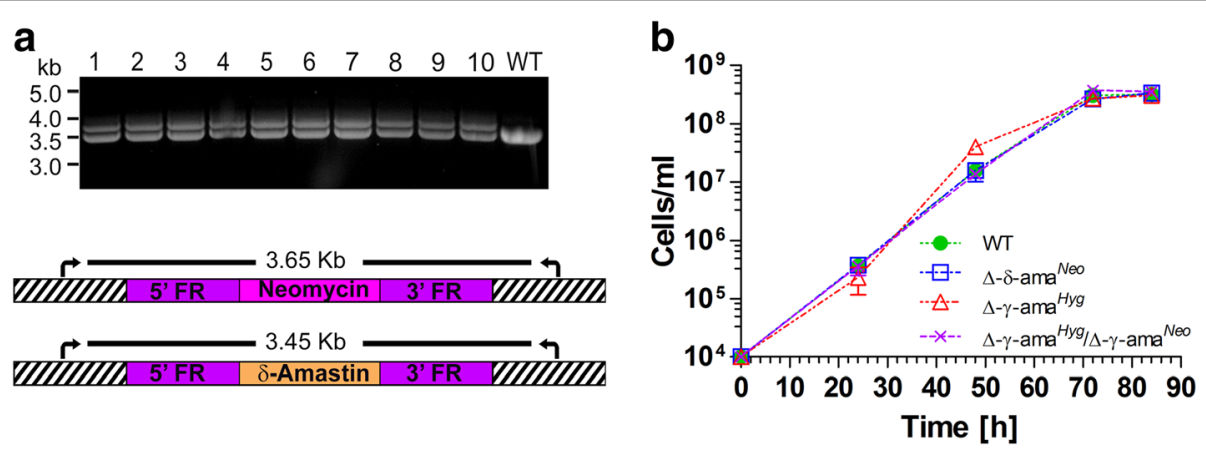

Fig. 4 (a) Stability of genomic insertion in A. deanei and (b) knock-out of the amastin genes does not affect growth of $A$. deanei. (a) Ten clones of the $\Delta-\delta$-Ama ${ }^{N e o}$ SKO were grown in the absence of G-418 for a period of two months. The gDNA was then extracted and the presence of neo tested by PCR. A single band at $3.45 \mathrm{~kb}$ corresponding to the $\delta$-amastin gene can be seen in the wild-type cells (WT), while an additional band at $3.65 \mathrm{~kb}$ corresponding to the insertion of neo appears in all $10 \Delta-\delta$-Ama ${ }^{\text {Neo }}$ clones examined (lanes 1-10). (b) Cells from mid-log phase cultures of the $\Delta$ - $\delta$-ama ${ }^{\mathrm{Neo}}$ and $\Delta$ - $\gamma$-ama ${ }^{\mathrm{Hyg}}$ SKOs and the $\Delta-\gamma$-ama ${ }^{\mathrm{Hyg}} / \Delta-\gamma$-ama ${ }^{\mathrm{NeO}}$ DKO cell lines were diluted to $1 \times 10^{4} \mathrm{cells} / \mathrm{ml}$ in fresh growth medium supplemented with $500 \mu \mathrm{g} / \mathrm{ml}$ of the corresponding drug(s) and cells were counted every day. Values represent an average and standard deviation of three independent experiments 


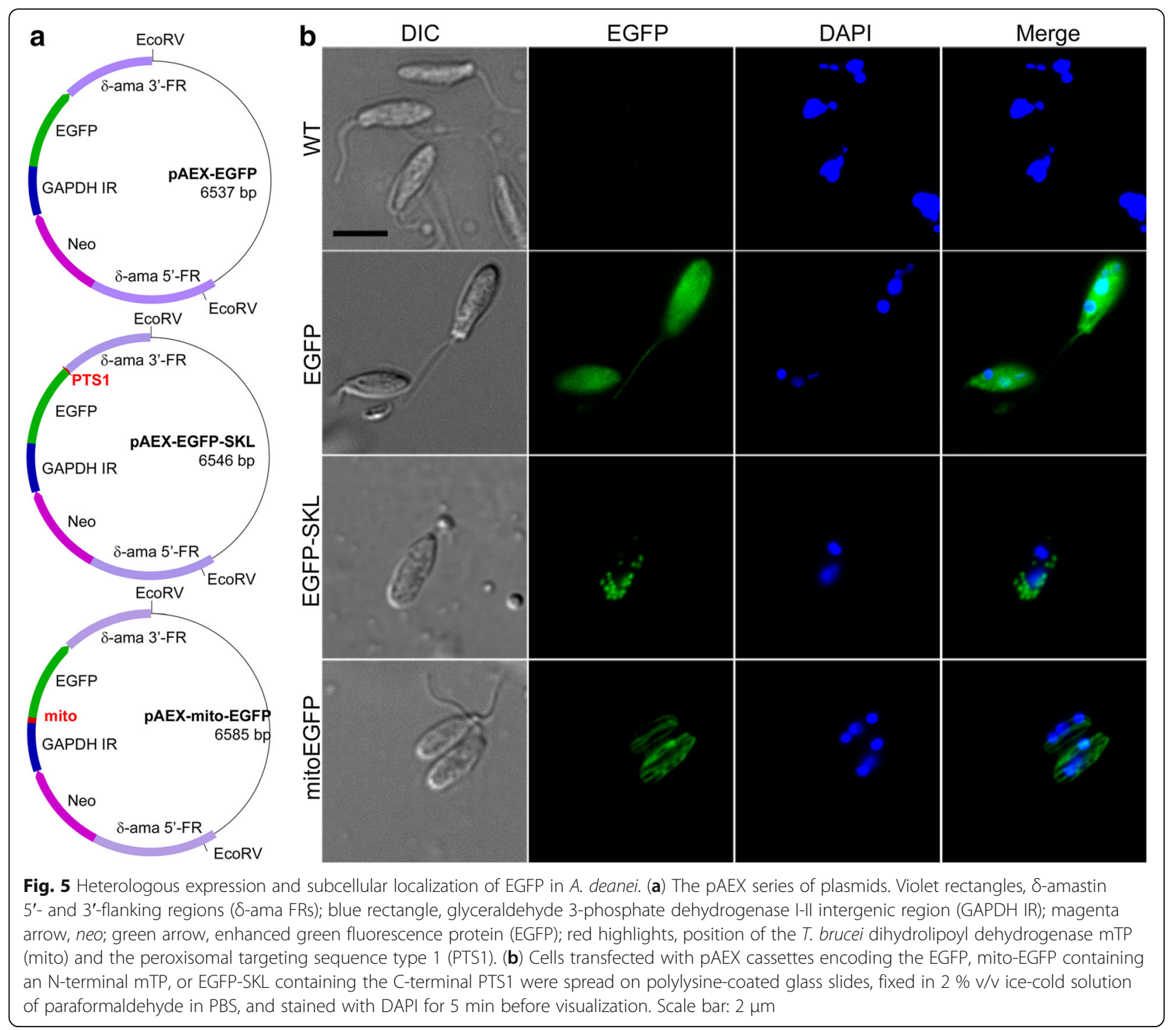

As assessed by epifluorescence microscopy, cells transfected with the pAEX-EGFP cassette showed the expected cytosolic localization of EGFP fluorescence (Fig. 5b). In contrast, cells transfected with the pAEX-EGFP-SKL cassette showed the characteristic punctate pattern of fluorescence in accord with localization of the EGFP to trypanosomatid glycosomes [36, 37], while cells transfected with the pAEX-mito-EGFP cassette showed a tubule-like fluorescence pattern that reflects the unique shape of the A. deanei mitochondrion [38] (Fig. 5b). These results demonstrate that (i) highjacking of the $\delta$-amastin locus was suitable for in vivo expression and localization of heterologous proteins in $A$. deanei, and that (ii) using the $A$. deanei GAPDH IR to drive expression of transgenes allows for the synthesis of stable mRNAs and the subsequent accumulation of the encoded fusion protein.
ETP1: a host-encoded protein specifically targeted to the endosymbiont

To test the hypothesis that host-encoded proteins in $A$. deanei are targeted to the endosymbiont, endosymbionts were isolated and subjected to proteomic analysis using tandem mass spectrometry. Comparative proteomic analysis of whole cell lysates versus purified endosymbionts revealed enrichment of the host-encoded ETP1 (UniProt accession S9VAC8) in the latter fraction (Table 1). Assignment of the sequence to nuclear contig number 14406 [25] and the presence of a typical SL at the 5'-end of the ETP1 mRNA clearly demonstrated its nuclear origin.

To confirm specific targeting of ETP1 to the endosymbiont, we constructed two expression vectors encoding ETP1 fused to the $\mathrm{N}$ - or C-terminus of EGFP (pAEXETP1-EGFP and pAEX-EGFP-ETP1; Fig. 6a). A. deanei cells transfected with these expression cassettes were 
Table 1 The host-encoded ETP1 is enriched in the purified endosymbiont fraction. 500 ng tryptic digested protein of each sample (whole cell lysate and purified endosymbionts from three independent experiments), was analyzed by tandem mass spectrometry (see Methods)

\begin{tabular}{|c|c|c|c|c|}
\hline \multirow[t]{2}{*}{ Protein } & \multirow{2}{*}{$\begin{array}{l}\text { Protein } \\
\mathrm{ID}^{a}\end{array}$} & \multirow[t]{2}{*}{ Subcellular localization ${ }^{b}$} & \multicolumn{2}{|c|}{ Averaged MS/MS spectral counts ${ }^{d}$} \\
\hline & & & Lysate & Endosymbiont \\
\hline$\overline{\mathrm{ETP}^{1}}$ & S9VAC8 & - & $12.3 \pm 2.5$ & $27.7 \pm 4.0$ \\
\hline a-Tubulin & S9WM11 & Cytoskeleton & $161.7 \pm 8.6$ & $7.7 \pm 7.2$ \\
\hline ATP synthase sub. $a^{e}$ & S9VLV1 & Mitochondria & $54.3 \pm 7.6$ & $5.7 \pm 5.1$ \\
\hline ATP synthase sub. $\beta^{e}$ & sguWU8 & Mitochondria & $84.7 \pm 2.9$ & $11.3 \pm 8.5$ \\
\hline $\mathrm{NADH}-\mathrm{FRD}^{f}$ & S9VM53 & Mitochondria \& glycosomes & $30.3 \pm 4.2$ & $14.0 \pm 12.3$ \\
\hline
\end{tabular}

${ }^{a}$ Protein identifier corresponding to the Uniprot Database (http://www.uniprot.org)

${ }^{b}$ Subcellular localization found in other trypanosomatid species

${ }^{c}$ Endosymbiont-targeted protein 1

${ }^{d}$ Average and standard deviations were calculated from three independent experiments

${ }^{e}$ Subunit $\alpha$ and $\beta$ of the mitochondrial ATPase complex

${ }^{f} \mathrm{NADH}$-dependent fumarate reductase

analyzed by fluorescence in situ hybridization (FISH) using a $5^{\prime}-\mathrm{Cy} 3$ labeled probe against the bacterial $16 \mathrm{~S}$ rRNA (Eub33) [39] in combination with an immunofluorescence assay using a GFP-specific primary antibody. Epifluorescence microscopy showed specific targeting of the $\mathrm{N}$ - and C-terminal fusions of ETP1 to EGFP to the bacterial endosymbiont, indicating that the targeting function of the ETP1 sorting signal (which has not been characterized) was maintained in both of the fusion proteins (Fig. 6b). The same fluorescence pattern was observed by direct analysis of the EGFP signal (Additional file 2: Figure S4), however, this type of analysis cannot be combined with FISH.

\section{Discussion}

Despite the prevalence of bacterial endosymbionts across eukaryotic phyla and their ecological and evolutionary relevance, molecular mechanisms mediating host-endosymbiont integration are largely unknown owing to a lack of effective molecular tools that enable functional studies of endosymbiotic systems. In this work, we focused on developing molecular biological tools for the trypanosomatid A. deanei, a promising model system for studying endosymbiosis. The ease of transfection, availability of full genome and transcriptome sequences, high frequencies of $\mathrm{HR}$, and rapid growth have allowed us to generate a toolbox for

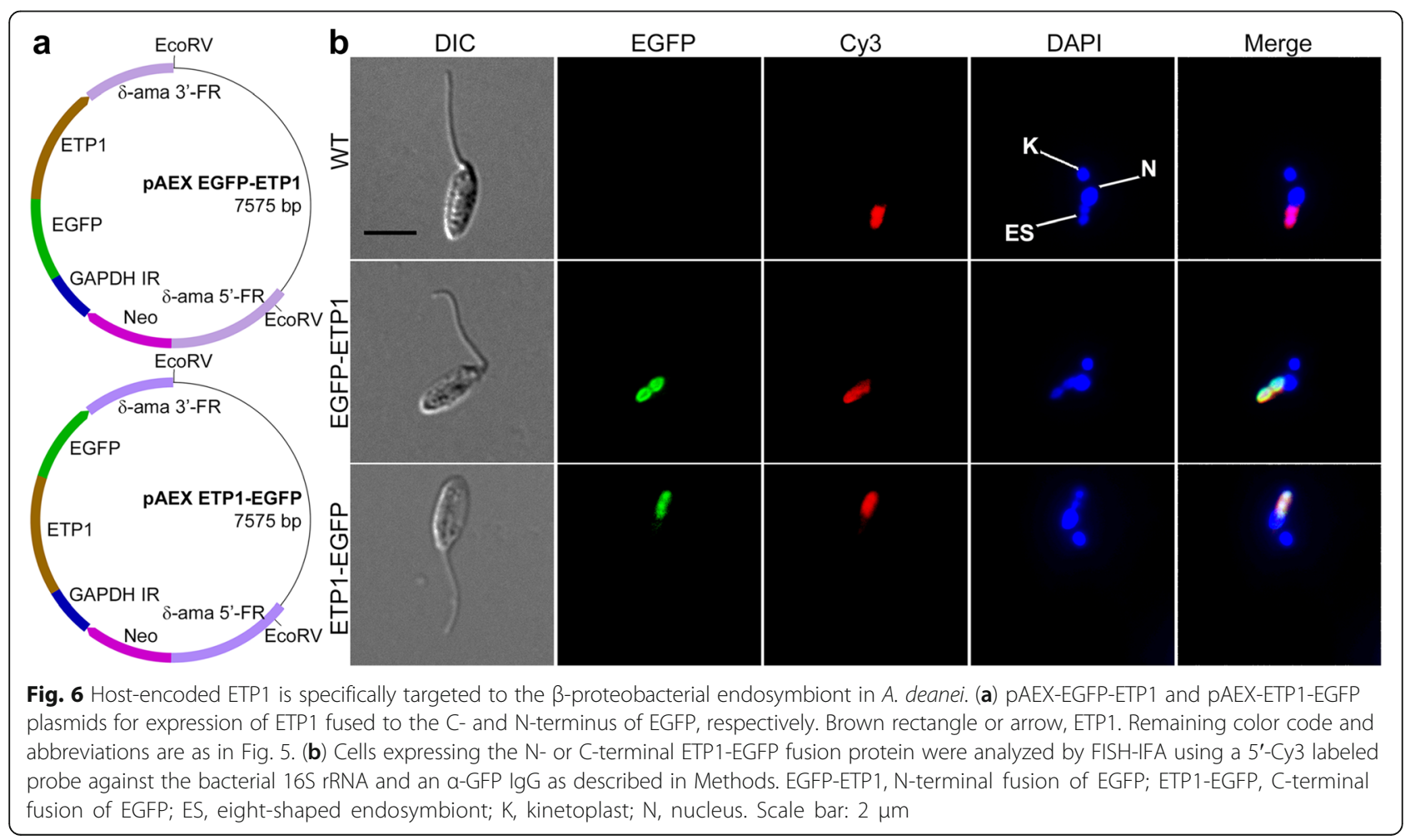


efficient genetic manipulation of $A$. deanei. We established electroporation protocols, hygromycin and neomycin resistances as markers for selection of transfectants, and identified the $\gamma$ - and $\delta$-amastin loci as suitable genome sites for insertion and high level expression of transgenes. In addition, we used these newly developed tools to perform protein localization studies over a short time frame (within a month) by heterologous expression of EGFP fused to various targeting signals, with the cassette encoding these constructs integrated into the $\delta$-amastin locus.

The ability to obtain SKO, DKO, and PKO cell lines in $A$. deanei and express fluorescent fusion proteins allows for the knock-out of specific genes, the expression of endogenous proteins with altered amino acid sequences, the establishment of over-expresser lines, the testing of heterologous proteins for activities/functions, and the localization of proteins to specific cellular compartments. These fundamental capabilities will enable, for the first time, the time and cost effective in depth dissection of the molecular mechanisms that shape the interactions between a eukaryotic host and its vertically inherited endosymbiont. Furthermore, there is the potential to expand the molecular toolbox for A. deanei. A recent study demonstrates that the RNAi machinery is functional in $A$. deanei and knock down of specific genes can be achieved by transfection of cells with double stranded RNAs [40]. Also the CRISPR-Cas9 system, which has recently been established in the closely related T. cruzi [27], can likely be applied to A. deanei with the tools already developed, which would help to efficiently knock out multiple genes simultaneously.

Using the newly developed tools, we firmly establish that the host-encoded protein ETP1 is specifically targeted to the endosymbiont of $A$. deanei. The absence of ETP1 orthologues in any other organism makes it difficult to predict a cellular function of this protein. Recently, it was shown that specifically inhibiting the $A$. deanei cell cycle or translation, affects the division of its endosymbiont [41]. This raises the speculative possibility that ETP1 and/or other nuclear-encoded proteins targeted to the endosymbiont might play a role in controlling its cell cycle.

Interestingly, in legume plants and insects with bacteriocyte-housed endosymbionts, proteins targeted to the bacterial endosymbionts contain an $\mathrm{N}$-terminal signal peptide (SP) that routes proteins to the secretory pathway [13-15]. In contrast, $A$. deanei ETP1 is specifically targeted to its intracellular $\beta$-proteobacterium in the absence of any apparent targeting signal at its $\mathrm{N}$ - or C-terminus. A similar situation was reported for nuclear-encoded photosystem I proteins that are targeted to the intracellular cyanobacterium-derived organelle in the amoeba P. chromatophora [12]. The presence or absence of SPs in symbiont-targeted proteins probably reflects an important difference between the various endosymbiotic systems. While Rhizobia in the legumes and bacteriocyte-housed endosymbionts in insects are compartmentalized within 'symbiosomes' (i.e. host-derived membranes that surround the endosymbiont), the bacterial endosymbionts of $A$. deanei and $P$. chromatophora are in the host cytoplasm and not encased in a host-derived membrane. A more rigorous analysis using methods with higher resolution such as immunogold electron microscopy will be necessary to establish subcellular localization of ETP1 within the endosymbiont.

\section{Conclusions}

The realization that symbiotic associations are ubiquitous in nature and critical to the evolution of eukaryotes makes it imperative to establish systems for elucidating the rules that govern the integration of an endosymbiotic bacterium into a eukaryotic host cell. Previous studies revealed targeting of host-encoded proteins to bacterial endosymbionts in plants (Archaeplastida), insects (Opisthokonta), and the amoeba P. chromatophora (Rhizaria). Here we report that also in the trypanosomatid A. deanei (Excavata), i.e. a member of a fourth eukaryotic superphylum, host-encoded proteins are routed to the bacterial endosymbiont. This finding suggests that the targeting of host proteins might be a general strategy of eukaryotic cells to gain control over and interact with a bacterial endosymbiont. In this work, we established $A$. deanei as a time and cost efficient reference system for in depth dissection of the molecular mechanisms that underlie host-endosymbiont interaction. Using this system to explore the partitioning of cellular functions, the trafficking of proteins and metabolites between the partner organisms and their regulatory integration, will be fundamental for our understanding of the biology of endosymbiosis and might provide insights into general principles that govern endosymbiosis as a biological phenomenon.

\section{Methods \\ Culture conditions}

A. deanei strain ATCC PRA-265, obtained from the American Type Culture Collection, was grown at $28{ }^{\circ} \mathrm{C}$ without shaking in Brain Heart Infusion (BHI, Sigma Aldrich) Broth supplemented with $10 \%$ horse serum (Sigma Aldrich) and $10 \mu \mathrm{g} / \mathrm{ml}$ hemin (Sigma Aldrich). Passages of the cells were made once their density reached $1 \times 10^{8}$ cells $/ \mathrm{ml}$. Cell numbers were determined by counting them in an improved Neubauer counting chamber.

\section{Generation of sequencing libraries, genome assembly, and RNAseq analysis}

An Illumina shotgun library (insert size 400-600 bp) from $A$. deanei total gDNA was sequenced with a single 
Illumina MiSeq run, yielding $2 \times 11,531,862$ paired-end 250 bp reads. Additionally, two Nextera Mate Pair libraries from 5-6 kb and 7-10 kb gDNA fragments were sequenced with a single Illumina MiSeq run, yielding $2 \times$ 11 million and $2 \times 1.2$ million paired-end 75 bp reads, respectively. The sequences were assembled de novo using Meraculous Assembler [42], v. 2.2.2.4 (available at https://sourceforge.net/projects/meraculous20/). The relatively modest level of polymorphism in the genome made it best suitable for assembly in diploid mode 1 which relies on identifying and traversing variant-induced "bubble" structures in the de Brujin contig graph. At an intermediate stage of the assembly process, contigs producing significant hits (Blastn) to the endosymbiont (Candidatus Kinetoplastibacterium crithidii TCC036E) genome, as well as PhiX contaminant contigs, were removed. Other notable assembly parameters used were k-mer size of 61 and the minimim k-mer depth cutoff of 8 , the latter one aimed at removal of likely erroneous k-mers.

Trizol-extracted $A$. deanei RNA from a mid-log phase culture grown in BHI medium was used to generate a complementary DNA (cDNA) TruSeq library and sequenced (1x100 cycles) using the Illumina HiSeq protocol. The transcriptome was assembled de novo from $98 \mathrm{M}$ quality filtered cDNA reads (phred score cutoff was 30 in at least $90 \%$ of the bases) using the Inchworm algorithm from the Trinity software package [43] (K-mer size was 25 and minimal assembly coverage was 3 ). The assembly generated $16 \mathrm{~K}$ transcripts of $>150 \mathrm{nt}$ that were annotated using Blast2Go [44]. Transcript abundance levels were estimated by mapping $161 \mathrm{M}$ quality filtered (phred score cutoff of 20 in at least $90 \%$ of the bases) cDNA reads back to the assembled transcripts using Bowtie software [45] essentially as described in [46], allowing for 2 mismatches within the first 28 nucleotides and a maximal sum of mismatch Phred quality values across all the alignment of 70 (-n 2 -e 70 -1 28, -best, and -strata options). All sequencing was performed at the Stanford Functional Genomics Facility.

\section{Antibiotic sensitivity of $A$. deanei}

Cells from mid-log phase cultures were diluted to $1 \times 10^{4}$ cells $/ \mathrm{ml}$ in fresh growth medium containing hygromycin B (Roth) or G-418 (Sigma Aldrich) at concentrations ranging from $50-400 \mu \mathrm{g} / \mathrm{ml}$. For each concentration, cells from 3 independent cultures were counted every $12 \mathrm{~h}$ over a 5 day period.

\section{Construction of plasmids}

The pAdea $\delta$-ama/Neo, $\delta$-ama/Hyg, $\gamma$-ama/Neo, and $\gamma$ ama/Hyg plasmids were generated by Gibson cloning using the pGEM-Teasy vector (Promega) as the backbone. Briefly, approximately $1 \mathrm{~kb} 5^{\prime}$ - and $33^{\prime}$-FRs of the $\delta$ - and $\gamma$-amastin genes were amplified from $A$. deanei
gDNA. The neo and hyg resistance genes were amplified from pEF1V5_HisA (Invitrogen) and pcDNA3.1/ Hygro(+) (Invitrogen), respectively. The primers used to generate these DNA fragments are given in Additional file 1: Table S2. The one-pot cloning reaction using the Gibson Assembly Master Mix (New England Biolabs) contained $0.15 \mathrm{pmol}$ of each purified PCR product for the 5'- and 3'-FRs, the resistance marker gene (neo or $h y g$ ), and the NcoI/PstI-restricted pGEM-Teasy vector. Five $\mu \mathrm{l}$ of the ligation reaction was used to transform chemically competent Escherichia coli cells by the standard heat shock protocol (see pGEM-Teasy manual, Promega) and correct assembly of fragments was verified by analytical digestion of the vectors followed by sequencing of the replacement cassettes.

To construct the pAEX series of expression plasmids, the glyceraldehydes-3-phosphate dehydrogenase intergenic region (GAPDH IR) was amplified from $A$. deanei gDNA using the primers 030 and 031 (Additional file 1: Table S2). The resulting fragment was sub-cloned into pJET (Thermo Scientific) to generate the pJET-GAPDH IR and sequenced. Generation of the pAEX-EGFP expression plasmid was accomplished by amplifying the $\delta$-amastin 5'-FR-neo and 3'-FR fragments from pAdea $\delta$-ama/Neo, the GAPDH IR from pJET-GAPDH IR, and the EGFP gene from the vector pUMA 1445 [47]. A total of $20 \mathrm{fmol}$ of each of the fragments and the pUMA 1467 backbone [47] were joined using the Golden Gate cloning system following restriction with $B s a \mathrm{I}$ [48]. The pAEX EGFP-SKL was obtained by adding three codons coding for the PTS1 SKL immediately before the EGFP stop codon (see primer 037). Conversely, pAEX mitoEGFP was constructed by adding the synthetic mTP from the T. brucei dihydrolipoyl dehydrogenase [35] immediately after the EGFP start codon (see primer 040). For the construction of pAEX EGFP-ETP1 and pAEX ETP1-EGFP, the ETP1 ORF was amplified from A. deanei gDNA, sub-cloned into pJET, and sequenced. An internal $B s a \mathrm{I}$ site in the ETP1 gene was removed by introducing a synonymous point mutation ( $G$ to $A$ ) at position 501 of the ORF. The BsaI-free ETP1 fragment was used to generate the vectors encoding the $\mathrm{N}$ - or $\mathrm{C}$ EGFP tagged fusion proteins.

Transfection of $A$. deanei and selection of clonal cell lines Cells grown to mid-log phase were collected and resuspended to $1 \times 10^{8}$ cells $/ \mathrm{ml}$ in buffer $\mathrm{T}$ [ $25 \mathrm{mM} \mathrm{4-(2-}$ hydroxyethyl)-1-piperazineethanesulfonic acid (HEPES), pH 7.6, $120 \mathrm{mM} \mathrm{KCl}, 0.15 \mathrm{mM} \mathrm{CaCl}_{2}, 10 \mathrm{mM} \mathrm{K}_{2} \mathrm{HPO}_{4}$, $2 \mathrm{mM}$ EDTA, and $5 \mathrm{mM} \mathrm{MgCl}$ ] or in solution for primary cells P3 (Lonza). A total of $100 \mu \mathrm{l}$ of cells resuspended in buffer $\mathrm{T}$ were mixed with $10 \mu \mathrm{g}$ of restricted cassette or full plasmid and electroporation was carried out using the program X-001 in the Nucleofector $2 \mathrm{~b}$ 
(Lonza). Alternatively, $1 \times 10^{6}$ cells were resuspended in solution P3 and mixed with 2-4 $\mu$ g of restricted cassette in a final volume of $20 \mu \mathrm{l}$ and electroporated using the program FP-158 in the Nucleofector 4D (Lonza). Following transfection, cells were transferred into $10 \mathrm{ml}$ of fresh growth medium and after a $24 \mathrm{~h}$ recovery period, antibiotics were added to a final concentration of $500 \mu \mathrm{g} /$ $\mathrm{ml}$ and were present throughout all the downstream steps unless indicated otherwise. After approximately 4 days, the transfected cells recovered and were sub-cultured in fresh medium every 3 days. At the third passage, the flagellates were diluted to a density of $1 \mathrm{cell} / \mathrm{ml}$ and aliquots of $200 \mu \mathrm{l}$ were separated in 96-well plates. Approximately 7 days later, clonal cultures were recovered and transferred to $10 \mathrm{ml}$ of fresh medium.

\section{Analysis of HR by PCR and Southern blot}

For PCR analysis, sets of primers were designed to anneal to genomic regions upstream and downstream of the 5 ' - and 3 '-flanking regions (FRs) of the target genes $(\gamma$ - and $\delta$-amastin), which were part of the plasmids used for transfection. Following transfection, clonal cultures of putative transformants were grown up and the gDNA of each was obtained by DNAzol treatment (Thermo Scientific) and then used as template to examine integration of transfected sequences. For Southern blots, the isolated gDNA from $5 \mathrm{ml}$ culture of the selected clones was isolated with the DNAeasy Blood \& Tissue kit (Qiagen) and $1 \mu \mathrm{g}$ was restricted with the indicated enzymes, separated on $0.8 \% \mathrm{w} / \mathrm{v}$ agarose gels, and transferred to nylon membranes (Nytran N Nylon Blotting Membrane, $0.45 \mu \mathrm{m}$; GE Healthcare Life Sciences). Labeling of the probe and DNA hybridization were performed according to the protocol supplied with the DIG-High Prime DNA Labeling and Detection Starter Kit II (Roche Applied Science) with the following hybridization temperatures: $\gamma$ amastin probe: $50^{\circ}, \delta$-amastin probe $52{ }^{\circ} \mathrm{C}$, and neo- and hyg-probe: $52.5^{\circ} \mathrm{C}$. Detection of the chemiluminescence on the developed membranes was performed in an ImageQuant LAS-4000 (GE Healthcare Life Sciences).

\section{Fluorescence microscopy}

For visualization of EGFP-expressing cell lines, an aliquot of approximately $20 \mu \mathrm{l}$ from cultures at $1 \times 10^{7}$ cells/ml was spread on a polylysine-coated slide and incubated for $10 \mathrm{~min}$. The same volume of freshly prepared ice-cold $4 \% \mathrm{w} / \mathrm{v}$ paraformaldehyde (PFA) in phosphate-buffered saline (PBS) was added and after 15 min, slides were washed $3 \mathrm{X}$ with PBS and stained for $5 \mathrm{~min}$ in PBS containing $1 \mu \mathrm{g} / \mathrm{ml}$ DAPI. Excess dye was removed by 3 washes in PBS. For fluorescence in situ hybridization coupled to immunofluorescence assay (FISH-IFA), cultures were adjusted to $2 \times 10^{7}$ cells $/ \mathrm{ml}$ with fresh medium, mixed 1:1 with an $8 \% \mathrm{w} / \mathrm{v}$ PFA solution in PBS and incubated for $30 \mathrm{~min}$ on ice. Aliquots of $20 \mu \mathrm{l}$ were spotted onto agarose-coated slides, air dried and FISH was performed as described in $[49,50]$ using the probe Eub338 (5'-GCTGCCTCCC GTAGGAGT-3') against the $16 \mathrm{~S}$ bacterial rRNA coupled at its $5^{\prime}$-end to Cy3 [39]. After FISH, the slides were thoroughly washed with PBS and blocked with the same buffer containing $5 \% \mathrm{v} / \mathrm{v}$ horse serum (HS) for $30 \mathrm{~min}$ followed by an additional $30 \mathrm{~min}$ incubation with anti-GFP rabbit IgG (Molecular Probes) at a dilution of 1:1000. After 3 washes of 5 min each with PBS $+5 \% \mathrm{HS}$, slides were incubated with Alexa Fluor 488 goat antirabbit IgG (ThermoFisher) at a dilution of 1:250 for $30 \mathrm{~min}$, washed $3 \mathrm{X}$ as before and stained with DAPI as described above. Images for localization studies were acquired using an epifluorescence microscope (Zeiss Axio Observer.Z1) and image manipulation and measurements were performed using the Metamorph software package (version 7, Molecular Devices).

\section{Purification of the endosymbiont}

Endosymbionts were isolated essentially as described before [51]. All steps were performed at $4{ }^{\circ} \mathrm{C}$ and centrifugation steps for the gradients were carried out in a Beckman JS-21 using the swinging bucket rotor JS-13.1. A total of $300 \mathrm{ml}$ of $A$. deanei culture grown to late-log phase was collected at $2,000 \times g$ for $10 \mathrm{~min}$, resuspended in $15 \mathrm{ml}$ buffer A (25 mM Tris- $\mathrm{HCl}, \mathrm{pH} \mathrm{7.5,} 20 \mathrm{mM}$ $\mathrm{KCl}$ and $2 \mathrm{mM}$ EDTA) containing $150 \mathrm{mM}$ of sucrose and a cocktail of protease inhibitors (Roche). After sonication, the lysate was centrifuged at 7,600 $\times g$ for $15 \mathrm{~min}$ and the pellet resuspended in $8 \mathrm{ml}$ of buffer A containing $250 \mathrm{mM}$ of sucrose (buffer B). A total of $2 \mathrm{ml}$ of the suspension was loaded on top of a discontinuous gradient of $2.5 \mathrm{ml} 0.8 \mathrm{M}$ and $5 \mathrm{ml}$ of $0.4 \mathrm{M}$ of sucrose in buffer A in $15 \mathrm{ml}$ glass tubes (Corex) and centrifuged at $760 \times g$ for $30 \mathrm{~min}$. The lower whitish band obtained in the $0.4 \mathrm{M}$ sucrose layer of the gradient was collected, centrifuged at $7,600 \times g$ for $15 \mathrm{~min}$, washed once with buffer A containing $400 \mathrm{mM}$ sucrose (buffer C), resupended in $2 \mathrm{ml}$ of the same buffer, and loaded on top of a percoll gradient of $2 \mathrm{ml}$ each $80 \%, 70 \%, 60 \%, 50 \%$, and $40 \%$, adjusted with the buffer A to $250 \mathrm{mM}$ final concentration of sucrose; the gradient was made in $15 \mathrm{ml}$ glass tubes (Corex). After centrifugation at 10,050 $\mathrm{x} g$ for $1 \mathrm{~h}$, the lower three bands located between 70 $60 \%$ percoll were collected, diluted $3-5 \mathrm{X}$ in buffer $\mathrm{C}$ and centrifuged at 7,600 $\times$ g for $15 \mathrm{~min}$. After removing the supernatant, the pellet was resuspended in $2 \mathrm{ml}$ of buffer $\mathrm{C}$ and $1 \mathrm{ml}$ was loaded onto an iodixanol gradient of $2.5 \mathrm{ml}$ each $30 \%, 27.5 \%, 25 \%$, and $22.5 \%$ diluted in buffer B. Following centrifugation (settings as for the previous percoll gradient), the pure endosymbiont fraction was collected from the 30-27.5 \% interphase and 
$27.5 \%$ iodixanol layer. This endosymbiont fraction was diluted 2X in buffer B, pelleted by centrifugation at 7,600 $\times$ g for $10 \mathrm{~min}$, and the pellet resuspended in $200 \mu \mathrm{l}$ of the same buffer and stored at $-20{ }^{\circ} \mathrm{C}$ for further experiments.

\section{Mass spectrometric analysis of protein samples}

Samples for mass spectrometry analysis were prepared as described in [52]. Peptides produced by trypsin digestion were separated on an Ultimate 3000 Rapid Separation Liquid Chromatography system (RSLC, Thermo Scientific, Dreiech, Germany) and analyzed on a $Q$ Exactive quadrupole-orbitrap mass spectometer (Thermo Scientific, Bremen, Germany) coupled online via a nanoelectrospray source. Data-dependent tandem mass spectra were acquired in positive mode and analyzed within the MaxQuant software environment (version 1.5.3.8, MPI for Biochemistry, Planegg, Germany) using standard parameters; label-free quantification was enabled and the UniProtKB proteome datasets for A. deanei (UP000015341) and its endosymbiont $\mathrm{Ca}$. Kinetoplastibacterium crithidii (UP000010479), which consist of 14,609 and 739 entries, respectively, were considered for protein identification.

\section{Additional files}

Additional file 1: Table S1. mRNA abundance levels of the 120 most abundant transcripts in A. deanei. Table S2. Primers used in this study. (PDF 169 kb)

Additional file 2: Figure S1. Sequences of the targeted $\gamma$ - and $\delta$ amastin ORFs. Figure S2. pAdea series of plasmids containing the neomycin and hygromycin replacement cassettes. Figure S3. High frequency of homologous recombination in A. deanei. Figure S4. EGFP fluorescence pattern suggests targeting of host-encoded ETP1 to the endosymbiont in A. deanei. (PDF $736 \mathrm{~kb})$

\section{Acknowledgments}

We thank Gereon Poschmann and Kai Stühler from the BMFZ Molecular Proteomics Laboratory for performing the mass spectrometric analyses of A. deanei samples.

\section{Funding}

This study was supported by Deutsche Forschungsgemeinschaft grant NO 1090/ 1-1 (to E.C.M.N.), National Science Foundation grant MCB-10370 (to A.R.G.), and the iGRAD Molecules of Infection (MOl) programme (to S.K.).

\section{Availability of data and material}

The genome dataset supporting the conclusions of this article is available at GenBank (http://www.ncbi.nlm.nih.gov/genbank/) under the accession LXWQ00000000.

\section{Authors' contributions}

JM, SK, DW, and ECMN performed the experiments; JC, EG, and DR assembled the genome; ECMN and ARG conceived the study; all authors contributed to writing the manuscript; all authors read and approved the final manuscript.

\section{Competing interests}

The authors declare that they have no competing interests.

\section{Consent for publication}

Not applicable.
Ethics approval and consent to participate

Not applicable.

\section{Author details}

${ }^{1}$ Department of Biology, Heinrich-Heine-Universität Düsseldorf, Universitätsstr. 1, 40225 Düsseldorf, Germany. ${ }^{2}$ Plant Genome Group, DOE Joint Genome Institute, 2800 Mitchell Drive, 94598 Walnut Creek, CA, USA. ${ }^{3}$ Department of Plant Biology, Carnegie Institution for Science, 260 Panama Street, 94305 Stanford, CA, USA.

Received: 18 July 2016 Accepted: 28 October 2016 Published online: 11 November 2016

\section{References}

1. Williams TA, Foster PG, Cox CJ, Embley TM. An archaeal origin of eukaryotes supports only two primary domains of life. Nature. 2013;504:231-6.

2. Yoon HS, Hackett JD, Ciniglia C, Pinto G, Bhattacharya D. A molecular timeline for the origin of photosynthetic eukaryotes. Mol Biol Evol. 2004;21:809-18.

3. Nowack ECM, Melkonian M. Endosymbiotic associations within protists. Phil Trans Royal Soc B. 2010;365:699-712.

4. Toft C, Andersson SGE. Evolutionary microbial genomics: insights into bacterial host adaptation. Nature Rev Genetics. 2010;11:465-75.

5. Nowack ECM, Grossman AR. Evolutionary pressures and the establishment of endosymbiotic associations. In: Bakermans C, editor. Microbial Evolution under Extreme Conditions. Berlin/Munich/Boston: Walter de Gruyter; 2015: p. 223-46.

6. McCutcheon JP, Moran NA. Extreme genome reduction in symbiotic bacteria. Nature Rev Microbiol. 2012;10:13-26.

7. Moya A, Pereto J, Gil R, Latorre A. Learning how to live together: genomic insights into prokaryote-animal symbioses. Nature Rev Genetics. 2008;9:218-29.

8. Alves JMP, Klein CC, da Silva FM, Costa-Martins AG, Serrano MG, Buck GA, Vasconcelos ATR, Sagot M-F, Teixeira MMG, Motta MCM, et al. Endosymbiosis in trypanosomatids: the genomic cooperation between bacterium and host in the synthesis of essential amino acids is heavily influenced by multiple horizontal gene transfers. BMC Evol Biol. 2013;13.

9. Husnik F, Nikoh N, Koga R, Ross L, Duncan RP, Fujie M, Tanaka M, Satoh N, Bachtrog D, Wilson ACC, et al. Horizontal gene transfer from diverse bacteria to an insect genome enables a tripartite nested Mealybug symbiosis. Cell. 2013; 153:1567-78.

10. Wilson ACC, Ashton PD, Calevro F, Charles H, Colella S, Febvay G, Jander G, Kushlan PF, Macdonald SJ, Schwartz JF, et al. Genomic insight into the amino acid relations of the pea aphid, Acyrthosiphon pisum, with its symbiotic bacterium Buchnera aphidicola. Insect Mol Biol. 2010;19:249-58.

11. Nowack ECM, Vogel H, Groth M, Grossman AR, Melkonian M, Gloeckner G Endosymbiotic gene transfer and transcriptional regulation of transferred genes in Paulinella chromatophora. Mol Biol Evol. 2011;28:407-22.

12. Nowack EC, Grossman AR. Trafficking of protein into the recently established photosynthetic organelles of Paulinella chromatophora. Proc Natl Acad Sci USA. 2012;109:5340-5.

13. Login FH, Balmand S, Vallier A, Vincent-Monegat C, Vigneron A, Weiss-Gayet $M$, Rochat D, Heddi A. Antimicrobial peptides keep insect endosymbionts under control. Science. 2011;334:362-5.

14. Nakabachi A, Ishida K, Hongoh Y, Ohkuma M, Miyagishima SY. Aphid gene of bacterial origin encodes a protein transported to an obligate endosymbiont. Curr Biol. 2014:24:R640-1.

15. Van de Velde W, Zehirov G, Szatmari A, Debreczeny M, Ishihara H, Kevei Z, Farkas A, Mikulass K, Nagy A, Tiricz H, et al. Plant peptides govern terminal differentiation of bacteria in symbiosis. Science. 2010;327:1122-6.

16. Narusaka Y, Narusaka M, Yamasaki S, Iwabuchi M: Methods to transfer foreign genes to plants, transgenic plants - advances and limitations. InTech 2012, DOI: 10.5772/32773. Available from: http://www.intechopen.com/ books/transgenic-plants-advances-and-limitations/methods-to-transferforeign-genes-to-plants

17. Cusson M. The molecular biology toolbox and its use in basic and applied insect science. Bioscience. 2008;58:691-700.

18. Votýpka J, Kostygov AY, Kraeva N, Grybchuk-leremenko A, Tesarova M, Grybchuk D, Lukeš J, Yurchenko V. Kentomonas gen. n., a new genus of endosymbiont-containing trypanosomatids of Strigomonadinae subfam. n. Protist. 2014;165:825-38.

19. Chang KP. Ultrastructure of symbiotic bacteria in normal and antibiotic treated Blastocrithidia culicis and Crithidia oncopelti. J Protozool. 1974;21:699-707. 
20. Motta MC, Catta-Preta CM, Schenkman S, de Azevedo Martins AC, Miranda K, de Souza W, Elias MC. The bacterium endosymbiont of Crithidia deanei undergoes coordinated division with the host cell nucleus. PLoS One. 2010;5, e12415.

21. Alves JM, Voegtly L, Matveyev AV, Lara AM, da Silva FM, Serrano MG, Buck GA, Teixeira MM, Camargo EP. Identification and phylogenetic analysis of heme synthesis genes in trypanosomatids and their bacterial endosymbionts. PLoS One. 2011;6, e23518.

22. Alves JMP, Serrano MG, da Silva FM, Voegtly L, Matveyev AV, Teixeira MMG, Camargo EP, Buck GA. Genome evolution and phylogenomic analysis of Candidatus Kinetoplastibacterium, the betaproteobacterial endosymbionts of Strigomonas and Angomonas. Genome Biol Evol. 2013;5:338-50.

23. Mundim MH, Roitman I. Extra nutritional requirements of artificially aposymbiotic Crithidia deanei. J Protozool. 1977;24:329-31.

24. Kostygov AY, Dobáková E, Grybchuk-leremenko A, Váhala D, Maslov DA, Votýpk J, Lukeš J, Yurchenko V. Novel trypanosomatid-bacterium association: Evolution of endosymbiosis in action. mBio. 2016;7:e1985-15.

25. Motta MC, Martins AC, de Souza SS, Catta-Preta CM, Silva R, Klein CC, de Almeida LG, de Lima CO, Ciapina LP, Brocchi M, et al. Predicting the proteins of Angomonas deanei, Strigomonas culicis and their respective endosymbionts reveals new aspects of the trypanosomatidae family. PLoS One. 2013;8:e60209.

26. Beverley SM. Protozomics: Trypanosomatid parasite genetics comes of age Nature Rev Genetics. 2003:4:11-9.

27. Burle-Caldas GA, Grazielle-Silva V, Laibida LA, DaRocha WD, Teixeira SM. Expanding the tool box for genetic manipulation of Trypanosoma cruzi. Mol Biochem Parasitol. 2015;203:25-33.

28. Clayton CE. Genetic manipulation of kinetoplastida. Parasitol Today. 1999;15: 372-8.

29. Araujo PR, Burle-Caldas GA, Silva-Pereira RA, Bartholomeu DC, Darocha WD, Teixeira SM. Development of a dual reporter system to identify regulatory cis-acting elements in untranslated regions of Trypanosoma cruzi mRNAs. Parasitol Int. 2011;60:161-9.

30. Boucher N, Wu Y, Dumas C, Dube M, Sereno D, Breton M, Papadopoulou B. A common mechanism of stage-regulated gene expression in Leishmania mediated by a conserved 3'-untranslated region element. J Biol Chem. 2002;277:19511-20.

31. de Paiva RMC, Grazielle-Silva V, Cardoso MS, Nakagaki BN, Mendonça-Neto RP, Canavaci AMC, Souza Melo N, Martinelli PM, Fernandes AP, daRocha WD et al. Amastin knockdown in Leishmania braziliensis affects parasitemacrophage interaction and results in impaired viability of intracellular amastigotes. PLoS Pathog 2015;11:e1005296.

32. Jackson AP. The evolution of amastin surface glycoproteins in trypanosomatid parasites. Mol Biol Evol. 2010;27:33-45.

33. Kelly JM, Ward HM, Miles MA, Kendall G. A shuttle vector which facilitates the expression of transfected genes in Trypanosoma cruzi and Leishmania. Nucleic Acids Res. 1992;20:3963-69.

34. Michels PA, Poliszczak A, Osinga KA, Misset O, Van Beeumen J, Wierenga RK, Borst P, Opperdoes FR. Two tandemly linked identical genes code for the glycosomal glyceraldehyde-phosphate dehydrogenase in Trypanosoma brucei. EMBO J. 1986:5:1049-56.

35. Long S, Jirku M, Ayala FJ, Lukes J. Mitochondrial localization of human frataxin is necessary but processing is not for rescuing frataxin deficiency in Trypanosoma brucei. Proc Natl Acad Sci USA. 2008;105:13468-73.

36. Makiuchi T, Annoura T, Hashimoto M, Hashimoto T, Aoki T, Nara T. Compartmentalization of a glycolytic enzyme in Diplonema, a nonkinetoplastid euglenozoan. Protist. 2011;162:482-9.

37. Galland N, Demeure F, Hannaert V, Verplaetse E, Vertommen D, Van der Smissen P, Courtoy PJ, Michels PA. Characterization of the role of the receptors PEX5 and PEX7 in the import of proteins into glycosomes of Trypanosoma brucei. Biochim Biophys Acta. 2007;1773:521-35.

38. de Souza W, Motta MC. Endosymbiosis in protozoa of the Trypanosomatidae family. FEMS Microbiol Lett. 1999;173:1-8.

39. Amann RI, Krumholz L, Stahl DA. Fluorescent-oligonucleotide probing of whole cells for determinative, phylogenetic, and environmental studies in microbiology. J Bacteriol. 1990;172:762-70.

40. Catta-Preta CMC, Pascoalino BdS, de Souza W, Mottram JC, Motta MCM, Schenkman S: Reduction of tubulin expression in Angomonas deanei by RNAi modifies the ultrastructure of the trypanosomatid protozoan and impairs division of its endosymbiotic bacterium. J Euk Microbiol 2016; Accepted Author Manuscript. doi:10.1111/jeu.12326.
41. Catta-Preta CM, Brum FL, da Silva CC, Zuma AA, Elias MC, de Souza W, Schenkman S, Motta MC. Endosymbiosis in trypanosomatid protozoa: the bacterium division is controlled during the host cell cycle. Front Microbiol. 2015;6:520.

42. Chapman JA, Ho I, Sunkara S, Luo S, Schroth GP, Rokhsar DS. Meraculous: De novo genome assembly with short paired-end reads. PLOS ONE. 2011;6.

43. Grabherr MG, Haas BJ, Yassour M, Levin JZ, Thompson DA, Amit I, Adiconis X, Fan L, Raychowdhury R, Zeng Q, et al. Full-length transcriptome assembly from RNA-Seq data without a reference genome. Nature Biotechnol. 2011:29:644-52.

44. Conesa A, Götz S, García-Gómez JM, Terol J, Talón M, Robles M. Blast2go: a universal tool for annotation, visualization and analysis in functional genomics research. Bioinformatics. 2005;21:3674-6.

45. Langmead B, Trapnell C, Pop M, Salzberg SL. Ultrafast and memory-efficient alignment of short DNA sequences to the human genome. Genome Biology. 2009;10

46. Van Verk MC, Hickman R, Pieterse CMJ, Van Wees SCM. RNA-Seq: Revelation of the messengers. Trends Plant Sci. 2013;18:175-9.

47. Terfrüchte M, Joehnk B, Fajardo-Somera R, Braus GH, Riquelme M, Schipper K, Feldbrügge M. Establishing a versatile Golden Gate cloning system for genetic engineering in fungi. Fungal Genet Biol. 2014;62:1-10.

48. Engler C, Kandzia R, Marillonnet S. A one pot, one step, precision cloning method with high throughput capability. PLoS One. 2008;3, e3647.

49. Cottrell MT, Kirchman DL. Community composition of marine bacterioplankton determined by $16 \mathrm{~S}$ rRNA gene clone libraries and fluorescence in situ hybridization. Appl Environ Microbiol. 2000;66:5116-22.

50. Fuchs BM, Pernthaler J, Amann R. Single cell identification by fluorescence in situ hybridization. In: Reddy CA, Beveridge TJ, Breznak JA, Marzluf G, Schmidt TM, Snyder LR, editors. Methods for general and molecular microbiology. 3rd ed. Washington, D.C: ASM Press; 2007. p. 886-96.

51. Novak E, Haapalainen EF, Dasilva S, Dasilveira JF. Protein-synthesis in isolated symbionts from the flagellate protozoan Crithidia deanei. J Protozool. 1988;35:375-8.

52. Poschmann G, Seyfarth K, Besong Agbo D, Klafki HW, Rozman J, Wurst W, Wiltfang J, Meyer HE, Klingenspor M, Stühler K. High-fat diet induced isoform changes of the Parkinson's disease protein DJ-1. J Proteome Res. 2014;13:2339-51.

\section{Submit your next manuscript to BioMed Central and we will help you at every step:}

- We accept pre-submission inquiries

- Our selector tool helps you to find the most relevant journal

- We provide round the clock customer support

- Convenient online submission

- Thorough peer review

- Inclusion in PubMed and all major indexing services

- Maximum visibility for your research

Submit your manuscript at www.biomedcentral.com/submit
Biomed Central 